\title{
INTELLIGENT AGENTS AND RISK BASED MODEL FOR SUPPLY CHAIN MANAGEMENT
}

\author{
Ion Smeureanu${ }^{1}$, Gheorghe Ruxanda ${ }^{2}$, \\ Andreea Diosteanu ${ }^{3}$, Camelia Delcea ${ }^{4}$, Liviu Adrian Cotfas ${ }^{5}$
}

\author{
Faculty Cybernetics, Statistics and Economic Informatics, \\ Bucharest Academy of Economic Studies, 010552 Bucharest, Romania

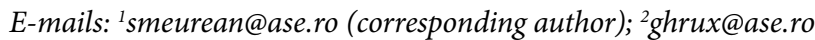 \\ ${ }^{3}$ andreea.diosteanu@gmail.com; ${ }^{4}$ camelia.delcea@yahoo.com; ${ }^{5}$ liviu.cotfas@ase.ro
}

Received 21 February 2012; accepted 14 April 2012

\begin{abstract}
This paper presents a software agent based framework's architecture for boosting performance in supply chain management applications. The framework is based on agent interaction and semantic web service composition. The purpose of such a platform is to develop flexible business applications for SCM transactions modeling, in collaborative and distributed economic systems. The interaction between agents is limited by a cybernetic model that takes into account several constraints one of the main being bankruptcy risk potential of the peer partner company.
\end{abstract}

Keywords: risk based model, supply chain, intelligent agents, neural network.

Reference to this paper should be made as follows: Smeureanu, I.; Ruxanda, G.; Diosteanu, A.; Delcea, C.; Cotfas, L. A. 2012. Intelligent agents and risk based model for supply chain management, Technological and Economic Development of Economy 18(3): 452-469.

JEL Classification: C02, D22.

\section{Introduction}

Nowadays, the enterprise environment is heavily influenced by the evolution of the IT\&C technologies. The main impact of these changes is on the collaborative nature of the economic activity. This results in an increased level of competition at a global scale. Therefore, adapting and efficiently taking advantage of these changes represents a real challenge for the top and medium management. The enterprise steering committee has to permanently be updated with the latest discoveries so that to obtain maximum satisfaction. 
In the context of dynamic business, maximizing and optimizing business performance is a critical requirement for profitability. The new economy considers enterprise interoperability along with efficient knowledge management strategies as one of the main prerequisites for improving the level of economic performance.

All the transformations that occur in the enterprise economic environment are closely connected and have a great influence over the globalization trend the economy is heading towards. The global market can be characterized by increased levels of interoperability that reflect into the integration of multiple and different information systems which are able to share, manipulate and combine knowledge so that to facilitate the enterprise collaboration process. Having given all the above facts, we can conclude that the very frequently used term "integrated company" is not of great interest anymore. Presently, it is substituted by collaborative information systems composed of business networks that are linked to independent partners that provide individual services and goods.

The changing economic conditions and the emerging global economy create a context in which companies that quickly and accurately evaluate new market opportunities and create innovative products and services can perform. Fully integrated traditional enterprises are being replaced by business networks in which every company is specialized in certain services or products (Gosain et al. 2005), (Nissen, Sengupta 2006).

In the economic systems that are based on enterprise interoperability, the business flow is more complex than in the non-collaborative ones. The business processes that compose the flow have to be designed as to take into account both the internal and the external economic environments. While the internal enterprise environment is composed of: activities such as marketing, production etc., actors (all the persons involved in the activities) and resources that characterize and assure its main functions, the external one consists of actions and behaviors that are part of the collaboration flow and establish the enterprise place and role in the global economic sector in which it performs. The supply chain activity is one of the most representative examples of enterprise collaboration and interaction.

In order to efficiently model and coordinate transactions in such complex economic systems, advanced collaborative software business solutions are required. The distributed nature of the collaborative economic environment can be represented and modeled by using web services and intelligent agents that interact with each other. According to Papazoglou, Kratz (2007) this requires that several web service operations or processes attain transactional properties reflecting business semantics, which are to be treated as a single logical (atomic) unit of work that can be performed as part of a business transaction.

This paper presents a software agent based framework architecture for boosting performance in supply chain management applications. The framework is based on agent interaction and neuronal networks. The purpose of such a platform is to develop flexible business applications for SCM transactions modeling in collaborative and distributed economic systems. The interaction between agents is limited by a cybernetic model that takes into account several constraints one of the main being bankruptcy risk potential of the peer partner company.

The first section of the article consists of a short literature review so that to establish the place of our research in the current international research trends. The following section 
describes the economic model that is applied. The last section presents the main elements of the multi-agent supply chain framework and how the economic model is integrated.

The innovative features of our proposal are the flexible agent search, the use of location and semantic annotation and also the use of the economic model that considers bankruptcy risk as one of the variables when evaluating the possible future business partner.

\section{Agent and semantic web service technologies applied in business flows}

When business processes cross over the boundaries of the organization they become more difficult to model and the software applications that are to be implemented in this situation are very complex. There are some main elements that have to be taken into consideration Papazoglou, Kratz (2007):

- Establish a common interaction language between distributed and distinct systems: unanimously agreed communication and business standards, common trading documents format, etc.

- Business protocols for message exchange that specify: flow of messages representing business activities among trading partners (without requiring any specific implementation mechanism). Collectively, business process protocols and associated data format and message exchange standards provide the means for automated, system-to-system exchange of data and messages between trading partners.

Nowadays, there are true businesses networks composed of independent partners that offer to the others their specific services or products. Therefore, we can assume that companies become product and customer oriented structures. In the context of dynamic business, maximizing and optimizing business performance is a critical requirement for profitability.

Software agents are complex autonomous software entities that behave and interact with each other in order to collaboratively fulfill the purpose of the entire multi-agent system. One important feature of multi-agent systems refers to their ability of decomposing complex problems into more easily manageable sub problems. This feature is particularly useful for representing supply chains as networks composed of autonomous business that negotiate, manufacture and distribute products and services, Bodea, Mogos (2007).

Using multi-agent systems in collaborative supply chain management systems implies modeling communication and cooperation between agents in order to allow demand-supply processes. As shown in Di et al. (2009) agents can communicate and interact with each other through ontology language.

The demand for flexible, adaptive multi-agent behavior has increased the challenges inherent in the design of multi-agent systems Bond, Gasser (1988). As a result, the attempt to automate the collaboration process between enterprises has been amplified. The payoff for meeting these amplified challenges is the creation of more capable, more robust multiagent systems.

In general, adapting the organization of a multi-agent system enables agents to overcome problems or improve performance by changing the pattern of information, control, and communication relationships among agents as well as the distribution of tasks, resources, 
and capabilities. For example, agents may be able to overcome agent failure (by restructuring collaborative decision-making to exclude failed agents), communication failure (by allowing agents awaiting orders to eventually take initiative), and under-performance (by allowing agents to establish new collaborations that may work better) Martin, Barber (2006).

Intelligent software agents have been used in enterprise independent software systems integration process, not only to assure an approach for functional integration, but also to facilitate the use of business intelligence and collaboration among enterprises for their communication, interaction, cooperation, pro-activeness, and autonomous intelligent decision making.

In order to achieve the objectives of the current enterprise interoperability trend, we propose a framework that combines web services and software agents so that to provide an efficient service selection, retrieval, composition and integration.

Multi-agent systems are closely connected to web service technology because they represent interoperable, portable and distributed solutions. Agents and web services may be related in different ways: agents use web services, web services are in fact agents or agents are composed of, deployed as, and dynamically extended by web services Martin et al. (2005).

\section{Supply chain management platform based on agents' interaction}

This paper illustrates an agent based software platform for modeling supply chain management application in the modern collaborative, knowledge based economic environment. Agents' behavior simulates human interaction, communication and negotiation processes.

The proposed framework enables the implementation of multi-agent supply chain systems that allow customers to easily identify suppliers that meet their business needs. All participants in the supply chain are modeled using software agents.

Similar to the real world business they represent on the internet, each agent has inputs and outputs. Outputs represent the services and products the agent offers, their price levels and technical features. Inputs consist in raw material, required-services or sub-assemblies needed in order to manufacture a specific output product or in order to provide a specific service.

In order to choose the best supplier for each input a series of features have to be taken into account. These features are combined in an evaluation function that is used to compute a score for each potential business supplier. Every agent will have its own evaluation function for selecting the most suitable business partners. The function is parameterized, so that each agent can choose different importance weights for the constraints according to its preferences.

In our paper, before applying the selection function we perform a classification of the companies based on their risk of bankruptcy. For the selection function we consider as variables: distance, price, technical features. This parameters can change based on the purpose of each business application. In this manner we assure an increased level of flexibility to our solution. In order to evaluate and predict the bankruptcy risk, we developed a wavelet neuronal network based model. 


\subsection{Bankruptcy Prediction Model}

In order to classify the identified suppliers into secure and non-secure ones we developed a binary classification model that is based on wavelet neuronal networks. Due to the competitive exchange economy, each firm can be seen as a producer or consumer looking to maximize either its profit or utility Rezvani, Analoui (2010). The algorithm has several stages that will be presented in detail below.

\section{Stage 1: Prerequisite phase - data collection}

This stage consists in creating a training set for the next phases of the algorithm. The set consists of forty five companies that are grouped into profitable, (thirty two companies) and less profitable ones (thirteen). We used the "profitable companies" term as a general term, these companies being characterized by sustainable growth and "proficient" economic strategy demonstrated by the values of certain indicators. For this we consider ten indicators that will be analyzed and in the variable selection phase will be selected only the ones that qualify to be part of the binary classification model. The computations are developed in MATLAB 7.9.0 and we took into account several data sources such as: BVB (2011), ANAF (2011), Mfin (2011), ListaFirme (2011), KTD (2011).

\section{Stage 2: Data mining and variables selection stage}

The data mining process consists of identifying a list of financial indicators that can be used to predict bankruptcy. Furthermore, over this stage we compute the values for indicators. Predictive variables selection is made in three steps:

Step 1: The bankruptcy prediction literature was reviewed and a number of 50 variables were selected, these variables representing the characteristics of profitability, liquidity, activity, stability, growth, trend, liability, structure, etc., see Table 1.

Table 1. Indicators used in financial distress Delcea (2010), Delcea, Scarlat (2010)

\begin{tabular}{ll}
\hline \multicolumn{1}{c}{ Category } & \multicolumn{1}{c}{ Indicator } \\
\hline Profitability & Gross income to sales \\
\hline & Earnings before interest and tax to total assets \\
\hline Return on total asset \\
\hline Financial expenses to liabilities \\
\hline Cost of sales ${ }^{*}$ Cost of sales growth ratio \\
\hline Net income to total interest \\
\hline Profit margin \\
\hline Cost of sales to net sales \\
\hline Financial expenses and normal profit to total assets \\
\hline Financial expenses growth rate to assets \\
\hline Non-operatory expenses growth rate to assets \\
\hline Net profit to equity
\end{tabular}


End of Table 1

\begin{tabular}{|c|c|}
\hline Category & Indicator \\
\hline \multirow[t]{7}{*}{ Activity } & Payables turnover \\
\hline & Inventory growth rate to sales \\
\hline & Current assets turnover \\
\hline & Fixed assets turnover \\
\hline & Inventory turnover \\
\hline & Total assets turnover \\
\hline & Total assets turnover ${ }^{*}$ sales growth rate \\
\hline \multirow[t]{3}{*}{ Liquidity } & Solvency ratio \\
\hline & Window coefficient \\
\hline & Cash flow to total liabilities \\
\hline \multirow[t]{5}{*}{ Stability } & Debt ratio \\
\hline & Long term debt ratio \\
\hline & Quick ratio \\
\hline & Net worth to total assets \\
\hline & Cash and cash equivalents to current liabilities \\
\hline \multirow[t]{7}{*}{ Growth } & Growth rate of primary business \\
\hline & Growth rate of total assets \\
\hline & Growth rate of sales \\
\hline & Total asset change ratio \\
\hline & Total asset growth rate \\
\hline & Interest increase ratio \\
\hline & Subsistence income to total assets \\
\hline Trend & Financial expenses growth \\
\hline \multirow[t]{4}{*}{ Structure ratios } & The proportion of fixed assets \\
\hline & The proportion of current assets \\
\hline & The proportion of equity to fixed assets \\
\hline & The proportion of current liability \\
\hline \multirow[t]{7}{*}{ Liability } & Current ratio \\
\hline & Asset liability ratio \\
\hline & Ratio of cash to current liability \\
\hline & Equity to debt ratio \\
\hline & Ratio of liability to tangible net asset \\
\hline & Interest coverage ratio \\
\hline & Ratio of liability to market value of equity \\
\hline
\end{tabular}


Step 2: Among them, eight variables were retained based on their availability on finding online necessary data;

In order to obtain the necessary data from the Internet, a web crawling application was developed. The application takes as input the CUI (fiscal code) and crawls the sites that were presented above. The web crawler module not only looks for data over the Internet, but also computes the financial indicators within the identified set based on the available data. For the training data set composed of 45 companies the application was able to identify data only for 10 indicators which will be presented in detail. Figure 1 presents a print screen from the web crawling application based on a single company search.

If no Fiscal code is entered the application crawls for the companies that we considered as a training data set. The results are displayed in Figure 2.

The following eight variables are the ones that manifested the great availability in finding their values through web crawling:

- X1 - Debt ratio (DR);

- X2 - Quick assets to total assets (QA2TA);

- X3 - Return on equity (ROE);

Financial Indicators for companies

Type the Fiscal Code: $24301329 \quad$ Search

\begin{tabular}{|lllllllll|}
\hline Company_Name & DR & QA2TA & ROE & NPE & FE2S & EPS & CAT & PM \\
\hline Impact Developer \& Contractor & 0.69 & 4.45 & 2.27 & 6.81 & 0.1634 & 0.0037 & 0.0543 & -0.6 \\
\hline
\end{tabular}

W3C css W30 ${ }_{1.1}^{\text {XHTML }}$

Fig. 1. Web crawler print screen displaying the results for a specific search

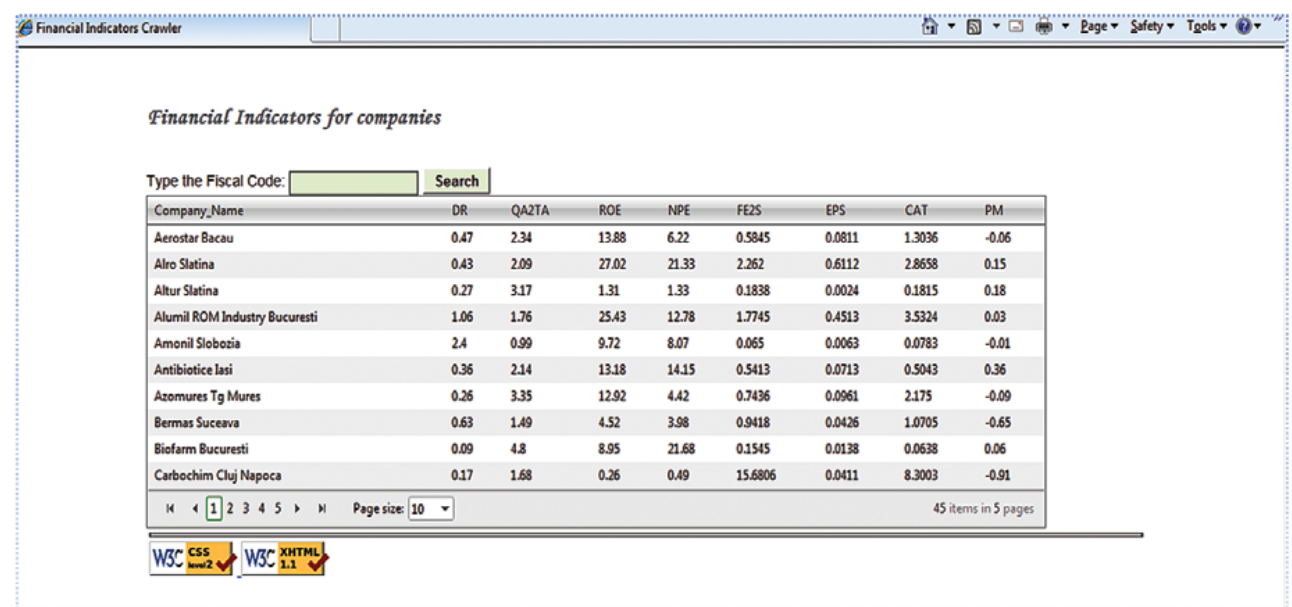

Fig. 2. Web crawl screenshot when no fiscal code is entered 
- X4 - Net profit to equity (NPE);

- X5 - Financial expenses to sales (FE2S);

- X6 - Earnings per share (EPS);

- X7 - Current assets turnover (CAT);

- X8 - Profit margin (PM).

Step 3: Using feature selection on standardized data for a specific significance level, a number of three variables are retained and used in the proposed model.

As Guyon, Elisseeff (2003) have identified the potential benefits of feature selection:

- facilitating data visualization and data understanding;

- reducing the measurement and storage requirements;

- reducing training and utilization times;

- defying the curse of dimensionality to improve prediction performance.

The feature selection algorithm is suited for training wavelet neuronal networks. In order to determine the most important features, we train a sample neural network using all the eight features presented at the previous step as shown in Figure 3. The network consists of three layers: input layer, hidden layer and output layer. All the nodes in each layer are fully connected to the nodes in the next layer. The input layer has 8 nodes corresponding to the features taken into consideration. The hidden layer has $m$ nodes and the output layer contains only one node, representing the classification. The network is trained using the considered firms in order to determine the weights between the nodes. We consider $w_{i j}$ the weight of a connection between the input node $i$ and the hidden node $j\left(i=1 \ldots n_{p} ; j=1 \ldots n_{h}\right)$ and $w_{j}^{\prime}$ the weight of the connection between the hidden node $j$ and the output node. In our case the number of input nodes, $n_{p}$ equals 8 , the number of variables taken into consideration.

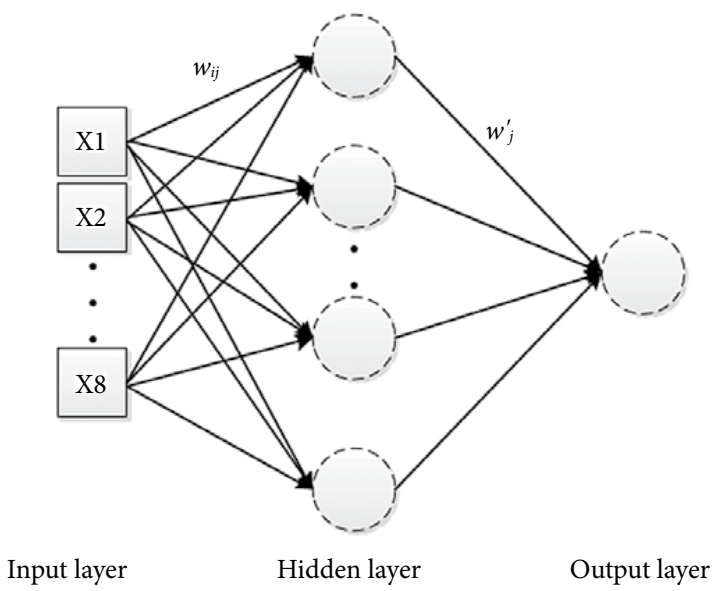

Fig. 3. Choosing the most important features based on their influence on the neural network output 
The most important features are the one for which the input has the highest absolute influence on the output. We can calculate the impact of the input node $i$ on the output of the hidden node $j$ using the following formula in which we divide the weight of the hidden to output link with the relevance of the $i$ to $j$ connection over all the inputs to hidden node $j$ :

$$
w^{*}=\frac{\left|w_{i j}\right|}{\sum_{i=1}^{n_{p}}\left|w_{i j}\right|}{ }^{\prime}\left|w_{i}^{\prime}\right| .
$$

For each input node we compute the importance indicator:

$$
h_{i}=\frac{\sum_{j=1}^{n_{h}} w^{\star} i j}{\sum_{i}{ }^{n_{p}}\left(\sum_{j=1}^{n_{h}} w^{*}{ }_{i j}\right)}{ }^{\star} 100
$$

(1) and (2) can be combined in a single equation:

$$
h_{i}=\frac{\sum_{j=1}^{n_{h}} \frac{\left|w_{i j}\right|}{\sum_{i=1}^{n_{p}}\left|w_{i j}\right|}{ }^{n_{p}}\left|w_{j}^{\prime}\right|}{\sum_{i}^{n_{h}}\left(\sum_{j=1}^{n} \frac{\left|w_{i j}\right|}{\sum_{i=1}^{n_{p}}\left|w_{i j}\right|}{ }^{\star}\left|w_{j}^{\prime}\right|\right)}{ }^{*} 100 .
$$

Based on the importance indicator, the following three variables were selected:

- X1 - Debt ratio; (stability);

- X7 - Current assets turnover; (activity);

- X8 - Profit margin; (profitability).

Debt ratio calculated as:

$$
D R=\frac{T L}{T A},
$$

where: $T L=$ Total liabilities; $T A=$ Total assets.

DR indicates what proportion of debt a company has relatively to its assets. It is categorized into the solvency and stability ratios category. Solvency may reveal the some firms' failure causes rooted in its financing policy. This ratio also gives an idea over company's potential risks in terms of debt load and has a negative relation with bankruptcy occurrence.

Current assets turnover (CAT) ratio determined by dividing the sales to the current assets is an efficiency ratio. A higher efficiency can be translated through higher profitability and better liquidity and finally to lower default risk. Etemadi et al. (2009)

$$
C A T=\frac{T S}{C A},
$$

where: $T S=$ Totals sales; $C A=$ Current assets. 
Profit margin (PM) calculated as net profits divided by sales or as net income divided by revenues. A higher level of this ratio means better coverage production costs and a lower default risk.

$$
P M=\frac{N P}{T S},
$$

where: $N P=$ Net profit; $T S=$ Total sales.

For the both considered categories (profitable and less profitable) and based on the initial data sample (forty five companies), the mean values of the X1, X7 and X8 indicators are calculated and their values could be found in Table 2 . These are going to be used in the next step, which deals with the binary classification of new firms.

Table 2. Means of the variables calculated for the two groups considered in the model

\begin{tabular}{lccc}
\hline \multicolumn{1}{c}{ Variable } & X1 & X7 & X8 \\
\hline Means of profitable firms & 0.6745 & 1.4403 & 0.2428 \\
\hline Means of less profitable firms & 0.7946 & 1.0955 & 0.0140 \\
\hline
\end{tabular}

Graphically, the mean values of the classification variables for each of the two representative sets are drawn in Figure 4.



Fig. 4. Mean values representation

In the variable selection phase we have identified a set of three variables that are best representing the situation in which a company can be found. Using the identified variables, we can pass to the next step: using a wavelet network classification model for predicting the future stage in which a firm could be found: profitable or less profitable.

\section{Stage 3: Wavelet neural network classification model}

Many approaches currently exist for predicting the corporate financial distress, usually based on discriminant analysis using linear functions. Such approaches have the disadvantage that the patterns need to be linearly separable and the samples must follow a multivariate normal distribution. Other approaches involve binary classification models Min, Jeong (2009) that 
involve the calculation of a similarity degree between a newly considered firm and the two considered sets in which a firm could be found. Neural networks emerged as a successful way to overcome such limitations Chauhan et al. (2009). They are built from many interconnected processing elements called neurons. The weights associated with the connections between the neurons model the input-output characteristics. Neural networks are used in Cimpoeru (2011) for credit risk assessment. Wavelet neural networks emerged as an approach that does not depend on the set of initial conditions used when defining the neural network structure. Figure 5 presents a representation of a wavelet function using Wolfram Mathematica.

An individual wavelet function is defined by the following formula:

$$
\psi^{a, b}(x)=\frac{1}{\sqrt{|\sigma|}}^{*} \psi\left(\frac{x-b}{a}\right) .
$$

Several methods to train wavelet neural networks - WNN exist including Differential evolution and Threshold accepting trained WNN Chauhan et al. (2009). A back propagation approach for training a normal neural network is presented in Ruxanda (2010).

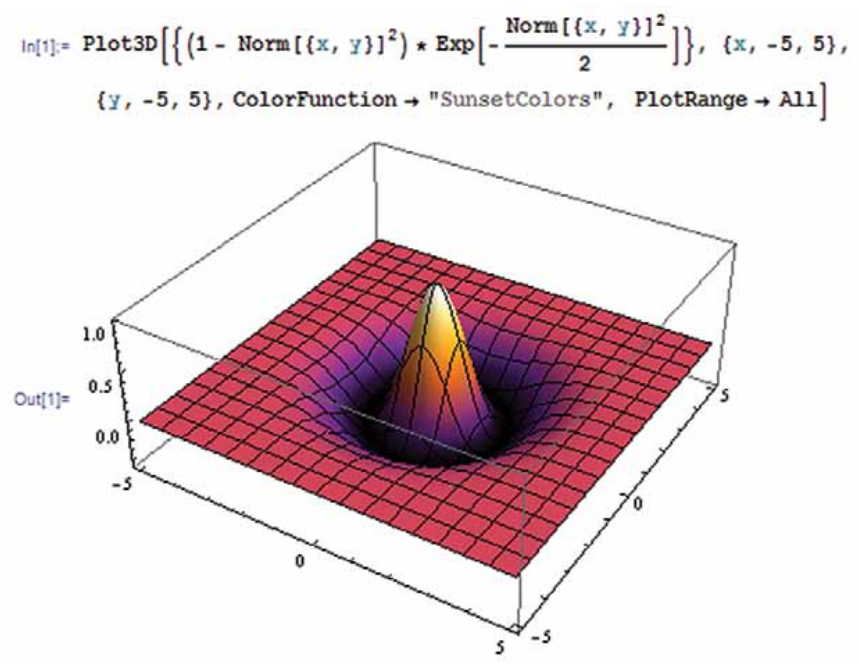

Fig. 5. Wavelet function represented using Mathematica

In order to train the network we use the following steps:

Step 1: We first assign random values for the connections between the input nodes and the hidden nodes and between the hidden nodes and the output node, $w_{i j} \in(0,1) ; w_{j}^{\prime} \in(0,1)$.

Step 2: The output of a sample $V_{k}, k=1, \ldots, n p$, where $n p$ is the number of samples, is calculated with the following formula:

$$
V_{k}=\sum_{j=1}^{n h n} w_{j}^{\prime} * f\left(\frac{\sum^{n i n} w_{i j} * x_{k i}-b_{j}}{a_{j}}\right),
$$

where: $k=1, \ldots, n p ;$ nin $=$ number of input nodes and $n h n=$ number of hidden nodes. 
Step 3: Reduce the error of prediction based on the training data set by adjusting the weights $w_{i j}, w_{j}^{\prime}$, jand the values for $a, b$. The error is computed as follows:

$$
E=\sqrt{\sum_{k=1}^{n p} \frac{\left(V_{k}-\hat{V}_{k}\right)}{V_{k}}} .
$$

Step 4: Return to Step 2 until the error $\mathrm{E}$ is as small as possible and the training phase can be considered completed.

The resulting $\mathrm{WNN}$ will have three input nodes corresponding to the selected values $\mathrm{X} 1$, $\mathrm{X} 7$ and $\mathrm{X} 8$ as shown in Figure 6.

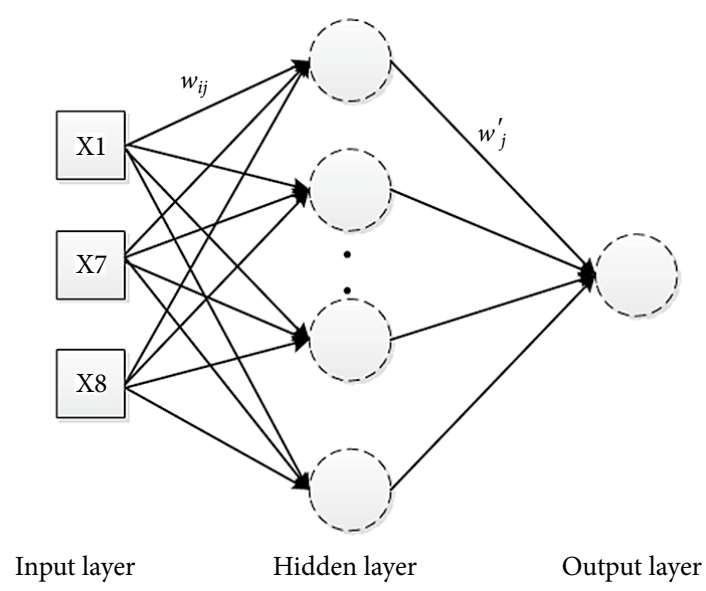

Fig. 6. Bankruptcy prediction model

The stages of the bankruptcy prediction and classification algorithm presented above are summarized in Figure 7.

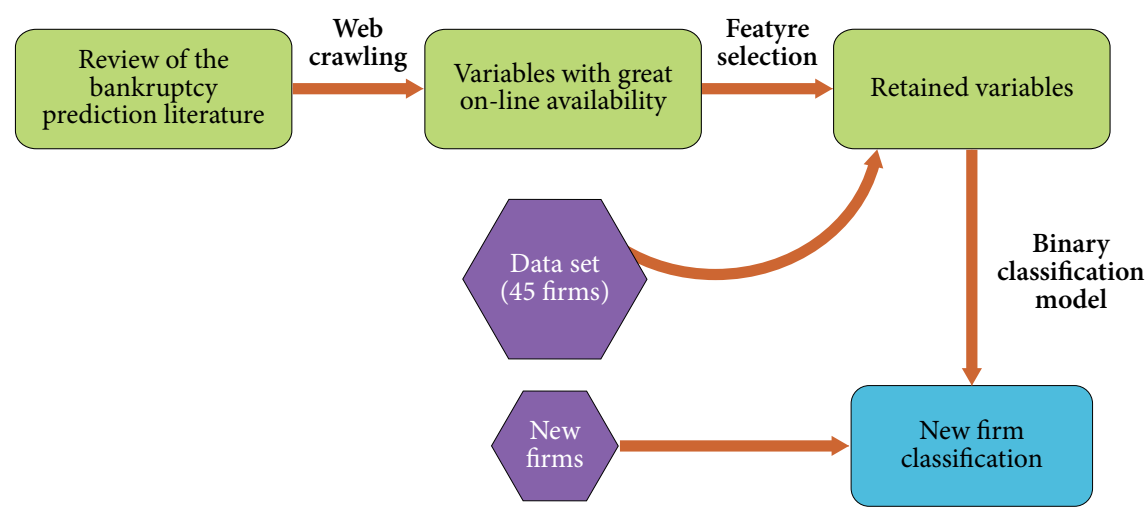

Fig. 7. Bankruptcy prediction and classification algorithm 


\subsection{Trading agents interaction process}

For example, consider, a manufacturer that develops Web service based solutions to automate the order and delivery business functions with its suppliers as part of a business transaction. The transaction between the manufacturer and its suppliers may only be considered as successful once all products are delivered to their final destination, which could be days or even weeks after the placement of the order, and payment has ensued.

According to Fox et al. (2000) a supply chain usually consists of suppliers, factories, warehouses, distribution centers, and retailers through which raw materials are acquired, transformed, and delivered to customers.

Although creating specialized agents for these categories implies several benefits we consider that this approach limits flexibility and the overall capacity of the system to model the real business entities. Taking into account that a participant in a supply chain might belong to several of the above mentioned categories and offer multiple services and products we have chosen to implement generic trading agents. Intelligent agents are used in Xiaolong et al. (2010) for trading in the construction projects field.

When evaluating offers, agents will first classify the providers based on their profitability by using the algorithm presented above. If a certain supplier is considered safe, the following function is used to evaluate the best offer Cotfas et al. (2010).

$$
\text { bestOffer }=\max _{i=1 . . m} \frac{\sum_{j=1}^{n} p_{l j} * \frac{M_{l j}\left(\alpha_{j k}\right)}{\max _{k=1 . . o_{j}} M_{l j}\left(\alpha_{j k}\right)}}{\sum_{j=1}^{n} p_{l j}},
$$

where: $m=$ number of suppliers; $n=$ number of technical features; $o_{j}=$ number of possible values for the feature $j ; p_{l j}=$ importance of feature $\mathrm{j}$ for trading agent $l ; \alpha_{j k}=$ possible values of the technical feature $j . M_{l j}:\left\{\alpha_{j k} ; j=1 . . n, k=1 . . o_{j}\right\} \rightarrow\{1 . .10\}=$ function evaluating the optimality of characteristic $j$ for trading agent $l$.

If one mandatory rule is not met, the offer is rejected and will no longer be taken into consideration during the evaluation process. Based on previous experience or user input, each agent maintains a list of trusted and mistrusted agents. Importance for the above mentioned parameters can be defined using the dedicated Supplier's Web Interface.

All agents can and usually perform several roles in the supply chain. In Figure 8 the agent called Trader 1 is a supplier for the agent Customer from whom it receives a service or a product request. If Trader 1 cannot complete the request by itself he can request additional services or subassemblies to other agents becoming thus a customer. Trader 2, 3 and 4 are possible suppliers for Trader 1 , but they also can become customers for other agents. If a trader agent cannot supply the requested service or product in the requested conditions, it returns a void offer.

Ontology Web Language (OWL) was used to semantically describe the products and services and also their technical characteristics. All configurations are done using the trader agents' web interface. 


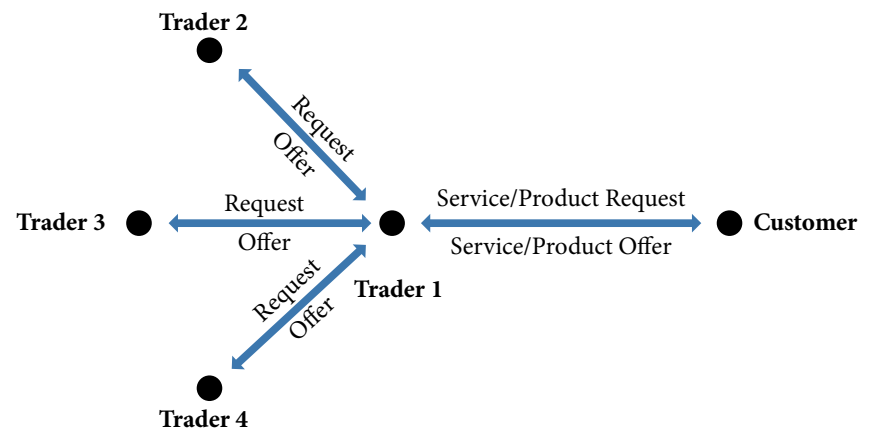

Fig. 8. Agent trading

Although location is considered an important aspect, many existing frameworks fail to use it at the full potential or omit it completely. We consider location import as it might have a big influence on transport costs and risks involved. It also helps us narrow the search when the requested service or product can be delivered only in certain areas. GPS coordinates are stored for all agents involved. Besides, for agents offering distribution services, GPS coordinates for the delivery areas are also stored as geographic shapes (polygon) using Geographic Markup Language (GML) standard format as defined by Open Geospatial Consortium (OGC). Using a standard format will allow us to integrate the framework with other applications like the one described in Dumitrescu et al. (2010).

\subsection{Identifying the best offer by using intelligent agent interaction}

The communication between agents is based on OWL ACL messages compliant with FIPA standards. The steps that are taken into account are presented below Chauhan et al. (2009).

Step 1: All Domain Directory Facilitator (DDF) agents register themselves with the main Directory Facilitator (DF) agent. Domain Directory Facilitator agents will keep information about service from a certain domain. A trader agent first queries the DF agent in order to obtain the available DDFs and then, it registers its services and products with the corresponding ones.

As shown in Figure 9, the framework is implemented in a distributed manner that allows having multiple DF agents running on different machines. Communication between the distributed components is implemented using web services for better interoperability across heterogeneous computing environments. The Web Service Agent (WSA) agent manages the translation between ACL messages and web service calls and constantly maintains a list of DF agents on other machines.

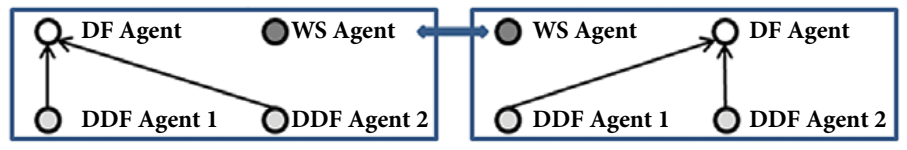

Fig. 9. Distributed agent-based architecture 
Step 2: As the supply chain is a customer demand-driven system, the flow starts from the customer's incoming orders. The customer agent first queries the DF and DDF agents on all machines for the list of supplier agents that provide a certain service or product.

Step 3: The customer agent sends its demand to the seller agents discovered in the previous step. The demand specifies the requested delivery addresses using GPS coordinates, the requested products, there technical features, quantity and maximum delivery date.

Step 4: Each contacted supplier agent analyzes the customer's demand and respond in case of match. First it compares the geographic position of the customer with its points of sales covered surface. Next, the seller agent compares the request products or services with his own data described using OWL. Using OWL proved to be a good solution to overcome data heterogeneity. Inference was implemented using Jena to better understand the customer's request. If the seller agent can't provide the requested service or product by itself (ex: it needs to buy subassemblies or raw materials), it will need to find suppliers. Thus, the seller agent becomes a customer for other seller agents and the process repeats starting with Step 2 (Figure 8).

Step 5: The customer agent continues to communicate and negotiate with the agents that positively respond. The offer evaluation takes into consideration both mandatory rules and the evaluation function (bestOffer). More than one seller agent might be selected if necessary in order to meet the required quantity. If the customer agent is not the initial customer, but a seller agent searching for necessary sub-assemblies or services, the algorithm continues with the selection of the best seller offer in the previous recursion step. The algorithm ends when the best seller offer evaluation is done by the initial customer agent.

As shown above, the algorithm is implemented in a recursive manner that allows each seller agent to become a customer agent if needed. This approach guarantees a high degree of flexibility in generating the supply chain. The customer agents can take into consideration a set of predefined rules when selecting suppliers like shown in Figure 10.

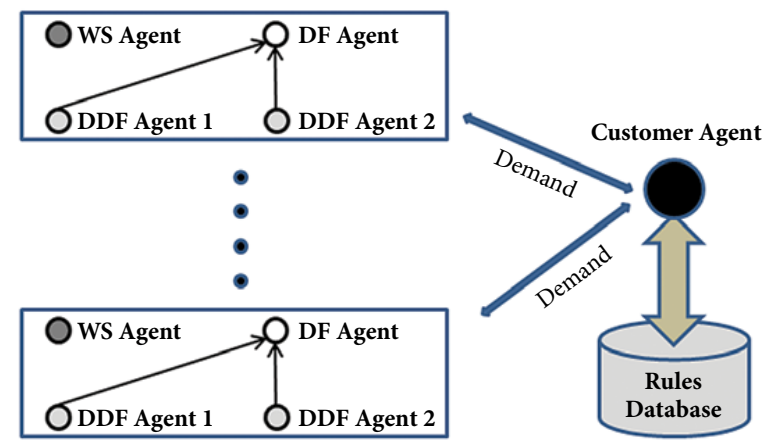

Fig. 10. Agent search in supply chains

Additional reasoning capabilities can be added to seller agent in order to enable the seller agents to adapt prices according to market situation so it can maximize its revenues by selling at appropriate prices. 


\section{Conclusions}

This paper presents and agent based framework that can be used for modeling Supply Chain Management application in the process of identifying the most convenient suppliers. The frameworks has an evaluation function for the best offer that is very customizable in the sense of enabling business application developers to take into account various types of constraints. Furthermore, this software solution also incorporates a bankruptcy prediction module based on neuronal networks that pre- classify potential suppliers based on their risk of going bankrupt, thus reducing the dimensions of the search space.

\section{Acknowledgement}

This article is one of the results of the research activity carried out under the frame of the project "Doctoral Program and $\mathrm{PhD}$ Students in the education research and innovation triangle". This project is co-funded by European Social Fund through the Sectorial Operational Program for Human Resources Development 2007-2013, coordinated by The Bucharest University of Economics.

\section{References}

Bodea, C.; Mogos, R. 2007. An electronic market space architecture based on intelligent agents and data mining technologies, Informatică Economică Journal 11(4): 115-118.

Bond, A.; Gasser, L. 1988. An analysis of problems and research in DAI, in Bond, A.; Gasser, L. (Eds.). Readings in Distributed Artificial Intelligence. San Mateo: Morgan Kaufmann Publishers Inc, 30-35.

Bucharest Stock Exchange (BVB) Official Site [online]. 2011. Available from Internet: www.bvb.ro

Chauhan, N.; Ravi, V.; Karthik, D. 2009. Differential evolution trained wavelet neural networks: application to bankruptcy prediction in banks, Expert Systems with Applications 36: 7659-7665. http://dx.doi.org/10.1016/j.eswa.2008.09.019

Cimpoeru, S. M. 2011. Neural networks and their application in credit risk assessment. Evidence from the Romanian market, Technological and Economic Development of Economy 17(3): 519-534. http://dx.doi.org/10.3846/20294913.2011.606339

Cotfas, L.; Diosteanu, A.; Smeureanu, I. 2010. Agent-based Collaborative Manufacturing, in The 32nd International Conference on Information Technology Interfaces. Dubrovnik: University of Zagreb, 163-168.

Delcea, C. 2010. Pattern recognition in financial distress with prior grey selection of variables, in IBIMA Conference. Istanbul, 120-130.

Delcea, C.; Scarlat, E. 2010. Finding companies' bankruptcy causes using a hybrid grey-fuzzy model, Economic Computation and Economic Cybernetics Studies and Research 44: 77-94.

Di, L.; Yang, W.; Yu, G.; Yue, P.; Zhao, P. 2009. Multi-Agent Systems for Distributed Geospatial Modeling, Simulation and Computing: Handbook of Research on Geoinformatics. Pennsylvania: Information Science Reference, 196-205.

Dumitrescu, S.; Smeureanu, A.; Diosteanu, A.; Cotfas, L. A. 2010. Adaptable network management system using GIS and network ontology, in 9th RoEduNet International Conference. Sibiu, 310-315.

Etemadi, H.; Rostamy, A.; Dehkordi, H. 2009. A genetic programming model for bankruptcy prediction: empirical evidence from Iran, Expert Systems with Applications 36: 3199-3207.

http://dx.doi.org/10.1016/j.eswa.2008.01.012 
Fox, M.; Barbuceanu, M.; Teigen, R. 2000. Agent-oriented supply-chain management, The International Journal of Flexible Manufacturing Systems 12: 165-188. http://dx.doi.org/10.1023/A:1008195614074

Gosain, S.; Malhotra, A.; El Sawy, O. 2005. Coordinating for flexibility in e-business supply chains, Journal of Management Information Systems 21(3): 7-46.

Guyon, I.; Elisseeff, A. 2003. An introduction to variables and feature selection, Journal of Machine Learning Research 3: 1157-1182.

KTD Invest Official Site [online]. 2011. Available from Internet: www.ktd.ro

Martin, C.; Barber, K. S. 2006. Adaptive decision-making frameworks for dynamic multi-agent organizational change, Autonomous Agents and Multi-Agent Systems 13(3): 391-428. http://dx.doi.org/10.1007/s10458-006-0009-8

Martin, D.; Burstein, M.; Mcilraith, S.; Paolucci, M.; Sycara, K. 2005. OWL-S and agent-based systems, in Extending Web Services Technologies: the Use of Multi-Agent Approaches. New York: Springer, 53-77.

Min, J.; Jeong, C. 2009. A binary classification method for bankruptcy prediction, Expert Systems with Applications 36: 5256-5263. http://dx.doi.org/10.1016/j.eswa.2008.06.073

National Agency for Fiscal Administration (ANAF) Official Site [online]. 2011. Available from Internet: www.anaf.ro.

Nissen, M.; Sengupta, K. 2006. Incorporating software agents into supply chains: experimental investigation with a procurement task, MIS Quarterly 30(1): 145-166.

Papazoglou, M.; Kratz, B. 2007. Web services technology in support of business transactions, Service Oriented Computing and Applications 1(1): 51-63. http://dx.doi.org/10.1007/s11761-007-0002-3

Public Finance Ministry (MFin) Official Site [online]. 2011. Available from Internet: www.mfinante.ro

Rezvani, M. H.; Analoui, M. 2010. An economic model for multi-service overlay multicast networks based on walrasian general equilibrium, Economic Computation and Economic Cybernetics Studies and Research 44: 139-161.

Romanian Companies Database (ListaFirme) Official Website [online]. 2011. Available from Internet: www.listafirme.ro

Ruxanda, Gh. 2010. Learning neural network perceptron with backpropagation algorithm, Economic Computation and Economic Cybernetics Studies and Research 16(4): 37-54.

Xiaolong, X.; Yingbo, J.; Lin, L.; Qiping, S. 2010. Cognition driven framework for improving collaborative working in construction projects: negotiation perspective, Journal of Business Economics and Management 11(2): 227-242. http://dx.doi.org/10.3846/jbem.2010.11

Ion SMEUREANU has graduated the Faculty of Planning and Economic Cybernetics in 1980, as promotion leader. He holds a PhD diploma in "Economic Cybernetics" from 1992 and has a remarkable didactic activity since 1984 when he joined the staff of Bucharest Academy of Economic Studies. Currently, he is a full Professor of Economic Informatics within the Department of Economic Informatics and the dean of the Faculty of Cybernetics, Statistics and Economic Informatics from the Academy of Economic Studies. He is the author of more than 16 books and an impressive number of articles. He was also project director or member in many important research projects. He was awarded the Nicolae Georgescu-Roegen diploma, the award for the entire research activity offered by the Romanian Statistics Society in 2007 and many others.

Gheorghe RUXANDA. PhD in Economic Cybernetics, is Full Professor and PhD Adviser within the Department of Economic Informatics and Cybernetics, The Bucharest Academy of Economic Studies. He graduated the Faculty of Economic Cybernetics, Statistics and Informatics, Academy of Economic Studies, Bucharest (1975) where he also earned his Doctor's Degree (1994). Had numerous research visits, as follows: Columbia University - School of Business, New York, USA (1999), Southern Method- 
ist University (SMU), Faculty of Computer Science and Engineering, Dallas, Texas, USA (1999), Ecole Normale Superieure, Paris, France (2000), Reading University, England (2002), North Carolina University, Chapel Hill, USA (2002). He is full professor of: Multidimensional Data Analysis (Doctoral School), Multidimensional Data Analysis (Master Studies), Modeling and Neural Calculation (Master Studies). Fields of Scientific Competence: evaluation, measurement, quantification, analysis and prediction in the economic field; econometrics and statistical-mathematical modeling in the economic-financial field; data mining, multidimensional statistics and multidimensional data analysis; pattern recognition and neural networks; risk analysis and uncertainty in economics; development of software instruments for economic-mathematical modeling.

Scientific research activity: over 35 years of scientific research in both theory and practice of quantitative economy and in coordinating research projects; 50 scientific papers presented at national and international scientific sessions and symposia; 65 scientific research projects with national and international financing; 70 scientific papers published in prestigious national and international journals in the field of economic cybernetics, econometrics, multidimensional data analysis, microeconomics, scientific informatics, out of which 9 papers being published in ISI - Thompson Reuters journals; 17 manuals and university courses in the field of econometrics, multidimensional data analysis, microeconomics, scientific informatics; 31 studies of national public interest developed within the scientific research projects.

Andreea DIOSTEANU holds a PhD diploma in the field of economics, specialized in informatics (artificial intelligence) applied in economics. She has graduated the Faculty of Economic Cybernetics, Statistics and Informatics in 2008 as promotion leader, with an average of 10. She is conducting research in Economic Informatics at Bucharest Academy of Economic Studies and she was also a pre-Assistant lecturer within the Department of Economic Informatics and .NET programmer (technical project manager) at TotalSoft. She participated in many student competitions both at national and international level obtaining a lot of first and second prizes. The most important competitions she was finalist in were Microsoft International Imagine Cup Competition, Software Design section (national finalist); Berkley University and IBM sponsored ICUBE competition where she qualified for the South Eastern Phase-Novatech. Furthermore, she also obtained the "N.N Constantinescu" excellence scholarship in 2007-2008 for the entire student research activity. She is the author of several articles published in national and international journals. Andreea obtained a full scholarship for the entire $\mathrm{PhD}$ program supported by the European Structural Funds under project POSDRU/6/1.5/S/11. She also attended a research stage at the Artificial Intelligence Group from Tor Vergata University of Rome.

Camelia DELCEA holds a PhD diploma in the Economic Cybernetics and Statistics Department at the Bucharest University of Economics. She holds a degree in Economics from the University of Economics, Bucharest (2008) and a teaching certificate from the same university. Her research activity is in the area of modeling and forecasting of a firm's "diseases" using the concepts and methods offered by multi-agent systems and includes more than 25 articles, an international IEEE Paper Award (IEEE GSIS Nanjing, China, 2009) and a full scholarship for the entire $\mathrm{PhD}$ program supported by the European Structural Funds under project POSDRU/6/1.5/S/11.

Liviu Adrian COTFAS holds a PhD diploma and a graduate of the Faculty of Cybernetics, Statistics and Economic Informatics. He is currently conducting research in Economic Informatics at Bucharest Academy of Economic Studies and he is also an Academic Assistent within the Department of Economic Informatics. Amongst his fields of interest are geographic information systems, genetic algorithms and web technologies. Liviu Adrian a full scholarship for the entire $\mathrm{PhD}$ program supported by the European Structural Funds under project POSDRU/6/1.5/S/11. 